\section{In Response to "Implementing Competency-Based Medical Education in Family Medicine: A Narrative Review of Current Trends in Assessment"}

\section{TO THE EDITOR:}

We applaud Dr Danilovich and colleagues for their well-researched review of current trends in assessment in family medicine competency-based medical education (CBME). The authors state that the most common concern for learners was "the need for better constructive feedback." We believe it is noteworthy that in the more than 30 years since academic family medicine launched discussion of CBME, the primacy of effective feedback, an essential element of formative assessment, remains.

In the 1980s, the STFM Task Force on Residency Education for the Future called for a transition to a competency-based curriculum. The work of the Task Force on CBME was largely informed by leaders in the field of mastery learning: Block, Airasian, Bloom, Carroll and others. ${ }^{2}$ Two major themes that were brought forward by the Task Force were a redefinition of aptitude that embraced the time variability by which learners achieve mastery, and second, the central role of formative evaluation and its focus on timely, nonjudgmental, competency-based feedback. The Task Force highlighted the importance of the teacherlearner relationship and the need to create a safe and respectful learning environment in order to facilitate mastery learning.

As follow-up to this effort, the STFM Task Force on Competency-Based Education in Family Medicine published its findings, which included the following recommendations: (a) a clear definition of competencies that must be mastered for successful completion of the curriculum, (b) use of formative evaluation instruments that help learners and teachers assess interval mastery, (c) allowance of sufficient time for learners to attain mastery, and (d) availability of a variety of teaching strategies for those who require additional instruction. ${ }^{3}$

Formative evaluation, particularly when coupled with encouragement and direction, sends a powerful message that the purpose for the interaction between teacher and learner is for the teacher to provide objective information to the learner with the intention of initiating a conversation about learning that is driven by the learner's self-examination of their current level of competence. It is an educational gift from teacher to learner that values the teacher-learner dyad and elevates learner safety while exposing weaknesses and areas for growth to the forefront. Tools, such as the gap analysis method, exist to enable teachers to create these safe educational relationships. ${ }^{4}$ The value of this approach, and the reason that lifting the method of CBME, beyond simply stating outcome competencies, is that it emulates highly effective medical care where the practitioner provides objective information to the patient to motivate a safe and respectful conversation of health within the patient, without judgment, bias, or prejudice. It is hypothesized that students who experience this method of education may then have a higher likelihood of practicing medicine with this attitude. Further work in CBME must include attention to the process of CBME in addition to a stating and assessing outcome competencies.

We believe that the time is right for the family medicine education research community to study the content of feedback, the process by which it is delivered, and the perceived quality of teacher-learner relationship on educational and clinical outcomes.

doi: 10.22454/FamMed.2021.353005

\section{Hershey S. Bell, MD, MSMedEd, FAAFP}

Lake Erie College of Osteopathic Medicine Erie, PA

Stanley M. Kozakowski, MD, FAAFP

American Academy of Family Physicians-Retired Leawood, KS

\section{References}

1. Danilovich N, Kitto S, Price DW, Campbell C, Hodgson A, Hendry P. Implementing competency-based medical education in family medicine: a narrative review of current trends in assessment. Fam Med. 2021;53(1):9-22. doi:10.22454/ FamMed.2021.453158

2. Block JH. Mastery learning: theory and practice. New York City, NY: Holt, Rinehart and Winston; 1971.

3. Bell HS, Kozakowski SM, Winter RO. Competency-based education in family practice. Fam Med. 1997;29(10):701-704.

4. Bell HS, Kozakowski SM. Teaching the new competencies using the gap analysis approach. Fam Med. 2006;38(4):238239. 


\section{Authors' Response to Drs Bell and Kozakowski}

\section{TO THE EDITOR:}

We thank Drs Bell and Kozakowski for their interest in our narrative review and for their thoughtful and positive letter to the editor. We appreciate how Drs Bell and Kozakowski highlighted some of our key observations concerning learners actively seeking out "critical feedback to help them accomplish the competency goals." We were particularly delighted to see that our message concerning the importance of studying "the content of feedback, the process by which it is delivered, and the perceived quality of teacher-learner relationship on educational and clinical outcomes" was well received.

Based on the thematic analysis of the literature included in our narrative review, we did indeed identify that the family medicine educational community faces several challenges with CBME assessment, including the need for and challenges to feedback for both learners and assessors (faculty). ${ }^{1}$ What is of particular interest is that those challenges go beyond family medicine education and reflect some of the current trends in the general medical educational literature regarding the feedback process $^{2,3}$ and the importance of peer-to-peer feedback for teaching. ${ }^{5}$ The latter phenomenon is something our team is currently investigating. Our preliminary results suggest that family medicine is leading the field in terms of producing scholarly work in the areas of needs assessment, identifying the benefits of feedback, and in engaging in innovative peerto-peer feedback design and practice. We believe that these three aspects of our inquiry into peer-to-peer feedback will build upon our CBME narrative review by complementing the current focus on competency definitions and outcomes, by focussing on the process of their performance and effects on and within the teacher-student dyad. As Bell and Kozakowski point out, "further work in CBME must include attention to the process of CBME in addition to stating and assessing outcome competencies." We believe that the time is right to pursue this agenda. We would argue that CBME is fundamentally performative in nature, in that CBME is constituted by how we practice it. In turn, the conditions under which CBME is practiced and the way it is performed affect the perception of its value for those involved, and, most importantly, shapes the nature of the way it is delivered and received. Ultimately, a greater understanding of the factors relating to CBME implementation effectiveness will lead to better design and performance as well as greater efficacy.

Again, we thank Drs Bell and Kozakowski for their letter. This is a clear call to action to promote the personal and professional development to achieve effective feedback for learners and faculty. We believe that in order to provide truly effective feedback and to build a coherent and integrated system of competency-based assessment, evaluation of the key contextual factors across the continuum of education to practice is of increasing importance in the field of continuing professional development. ${ }^{1}$ doi: 10.22454/FamMed.2021.793258

Simon Kitto, PhD

Natalia Danilovich, MD, PhD, MSc

Paul Hendry, MD, MSc, FRCSC

Office of Continuing Professional Development

Department of Innovation in Medical Education

University of Ottawa

Ottawa, Ontario, Canada

\section{References}

1. Danilovich N, Kitto S, Price DW, Campbell C, Hodgson A, Hendry P. Implementing competency-based medical education in family medicine: a narrative review of current trends in assessment. Fam Med. 2021;53(1):9-22. doi:10.22454/ FamMed.2021.453158

2. Archer JC. State of the science in health professional education: effective feedback. Med Educ. 2010;44(1):101-108. doi:10.1111/j.1365-2923.2009.03546.x

3. Bing-You R, Hayes V, Varaklis K, Trowbridge R, Kemp H McKelvy D. Feedback for learners in medical education: what is known? A scoping review. Acad Med. 2017;92(9):1346-1354. doi:10.1097/ACM.0000000000001578

4. Newman LR, Roberts DH, Frankl SE. Twelve tips for providing feedback to peers about their teaching. Med Teach. 2019;41(10):1118-1123. doi:10.1080/0142159X.2018.1521953 